\title{
Helicobacter pylori: the size of the problem
}

\author{
J Parsonnet
}

\section{Introduction}

My task is to describe the magnitude of the problem Helicobacter pylori poses worldwide. This is a daunting assignment for, while it would be relatively simple to summarise the prevalence of $H$ pylori, to characterise those at risk for infection, and to delineate incidence trends, it is far more difficult to quantify the actual disease that $H$ pylori causes. Certainly, $H$ pylori is an extraordinarily common infection. Its mere commonness, however, is not in itself a problem. Rather, it is the propensity $H$ pylori has for causing illness that determines its public health significance. Unfortunately, for several reasons, the total extent of disease worldwide is far more difficult to quantify than the amount of infection. Firstly, H pylori related diseases (for example, ulcer disease) are often treated empirically without resorting to diagnostic testing. There are, therefore, very incomplete data on the incidence and corresponding morbidity for these processes. Secondly, because some very common diseases or syndromes (for example, atherosclerosis, dyspepsia, and diarrhoea) are as yet only equivocally linked to infection, the true magnitude of $H$ pylori's consequences are not known. Finally, it is possible, although as yet unproved, that $H$ pylori has some beneficial effects to counterbalance its detrimental effects. ${ }^{1}$

The epidemiology of $\mathrm{H}$ pylori-how many people are infected?

$H$ pylori infection is extremely common worldwide. By some estimates, over one half of the world is infected with this organism. ${ }^{2}$ Prevalence can vary widely, however, between and within population groups. In some developing countries, most children are infected by 10 years of age and infection is almost universal by mid-life. ${ }^{3}$ In industrialised countries, however, prevalence of infection is considerably lower. This is not meant to imply that infection is rare in these countries, however, as even in the United States, Europe and Oceania, at least one third of the population is likely to be infected.

Prevalence of infection increases with advancing age. In some populations, a disproportionately high prevalence of $\mathrm{H}$ pylori infection is observed in those over 40 . This seems to reflect a birth cohort effect-that is, transmission of this chronic infection was more common years ago than it is today. ${ }^{4-6}$ In other populations, however, the elderly (those older than 60 or 70) seem to have a lower rate of infection than would have been anticipated. While this, too, may represent a birth cohort or period effect, a more likely explanation is that infection is lost as $H$ pylori's niche in the normal gastric architecture is destroyed by progressive inflammatory damage
Overall, H pylori incidence has been decreasing in industrialised countries over recent generations. According to Banatvala et al, the rate of decline may be as high as $26 \%$ per decade. ${ }^{5}$ Seroconversion studies from the 1990's indicate that only $0.4 \%$ of uninfected adults acquire $H$ pylori each year. ${ }^{7}$ In children, however, the incidence may be higher. Thus, many now consider $H$ pylori a predominantly childhood infection that persists throughout life. Yet, even in children, the likelihood of infection seems to be diminishing as the century draws to a close.

Other demographic factors have also been linked to infection. Several large epidemiological studies indicate a 5-20\% higher prevalence of infection in males than in females. ${ }^{8-10}$ Although this has not been uniformly reported, it could partially explain observed sex differences in propensity to duodenal ulcer and gastric cancer. Virtually all studies to date have shown an inverse relation between $H$ pylori infection and socioeconomic status. ${ }^{11}{ }^{12}$ Socioeconomic status during childhood serves as a particularly good gauge of $H$ pylori risk. ${ }^{13}$ In the United States, African-Americans and Hispanics exhibit higher rates of infection than do non-Hispanic whites. ${ }^{812} 14$ Racial/ethnic variations in $H$ pylori prevalence have also been observed outside the United States. ${ }^{15}{ }^{16}$ The reasons for racial/ethnic differences are not understood. Socioeconomic conditions during childhood, as measured by household crowding and parental income, are thought to play an important role. A genetic component to infection is also possible. ${ }^{8}$ A comparison of $H$ pylori concordance in monozygotic and dizygotic twins suggested that hereditability may explain $57 \%$ of infection prevalence. ${ }^{17}$

\section{The consequences of $\boldsymbol{H}$ pylori}

infection-how much sickness?

An increasingly large number of diseases have been ascribed to infection with $H$ pylori. Some are well documented, others less well so. Prevalently accepted are roles for $H$ pylori in duodenal ulcer, gastric ulcer, gastric adenocarcinoma, and gastric lymphoma. Less well accepted are its role in non-ulcer dyspepsia and its more indirect influences on coronary artery disease, rosacea, diarrhoeal diseases in children in developing countries, and hepatic encephalopathy. ${ }^{18-23}$ These latter conditions have all been epidemiologically linked to infection but a causal role for the organism has not been proved. Yet, if $H$ pylori is confirmed as even a weak causal factor in dyspepsia, heart disease, diarrhoea and/or encephalopathy, the overall importance of the organism will rise dramatically as these conditions engender high worldwide morbidity and considerable medical expenditure.
Room T225,

Stanford University,

Stanford, CA

J Parsonnet 
Table 1 Proportion of disease worldwide attributable to Helicobacter pylori infection, adjusted for sensitivity and specificity of diagnostic tests

\begin{tabular}{|c|c|c|c|c|c|c|c|c|}
\hline & $\begin{array}{l}\text { Estimated } \\
\text { new cases } \\
\text { annually }\end{array}$ & $\begin{array}{l}\text { Per cent } \\
\text { distal } \\
\text { stomach }\end{array}$ & $\begin{array}{l}\text { Number } \\
\text { potentially linked } \\
\text { to H pylori }\end{array}$ & $\begin{array}{l}\text { H pylori } \\
\text { prevalence (\%) }\end{array}$ & $\begin{array}{l}\text { RRs as reported in } \\
\text { meta-analyses }\end{array}$ & $\begin{array}{l}\text { Sensitivity and } \\
\text { specificity of } H \text { pylori } \\
\text { tests (\%) }\end{array}$ & $\begin{array}{l}\text { Adjusted } \\
\text { RR }\end{array}$ & $\begin{array}{l}\text { Adjusted PAR } \\
(\%)\end{array}$ \\
\hline $\begin{array}{l}\text { Gastric adenocarcinoma } \\
\text { Developing countries }\end{array}$ & 559000 & 90 & 503100 & 75 & 1.5 & 85 & 5.1 & 68 \\
\hline $\begin{array}{l}\text { Industrialised countries } \\
\text { Duodenal ulcer diseaset }\end{array}$ & 340000 & 60 & 204000 & 35 & 3.0 & 90 & 5.1 & 35 \\
\hline All countries & 6000000 & NA & 6000000 & 60 & 3.3 & 90 & 6.3 & 76 \\
\hline
\end{tabular}

Adapted from ${ }^{*}$ Pisani and colleagus ${ }^{2}$ and $\dagger$ Kurata and Nogawa. ${ }^{30}$

PAR, population attributable risk per cent; $R R$, relative risk.

If one considers only the diseases most strongly linked to $H$ pylori, gastric adenocarcinoma and duodenal ulcer disease, it is still evident that $H$ pylori infection imposes a heavy toll on world health. Gastric adenocarcinoma is the second leading cause of death from cancer worldwide. According to the International Agency for Research on Cancer, gastric cancer afflicts 900000 people annually, most of whom will die of their disease. ${ }^{2}$ Data on duodenal ulcer disease are fewer but indicate that between 0.1 and $0.2 \%$ will develop an ulcer annually and roughly $2-5 \%$ will have an ulcer at some time in their life. If these rates are extrapolated to the world population, then at least 6000000 duodenal ulcers occur annually and at least 120000000 people suffer from the disease at some point; up to 200000 will die each year from perforation or bleeding. ${ }^{24}$

Yet, not all gastric cancers or duodenal ulcers can be ascribed to $H$ pylori. Moreover, the proportion of disease caused by infection varies from population to population. For example, a group in Rochester recently reported finding $H$ pylori in only $30 \%$ of duodenal ulcers. ${ }^{25}$ Similarly, investigators from Johns Hopkins found $\mathrm{H}$ pylori in only $50 \%$ of patients with duodenal ulcer (in $25 \%$ of whites) and, in a prospective study, investigators from Harvard reported $H$ pylori in only $60 \%$ of physicians who developed duodenal ulcer. ${ }^{26}{ }^{27}$ These studies contrast with the $90 \% \mathrm{H}$ pylori prevalence previously presumed in duodenal ulcer patients. To complicate the issue further, Laine $e t$ al reported $20 \%$ recurrence of duodenal ulcer in subjects whose initial $H$ pylori infection had been successfully eradicated. ${ }^{28}$ Thus, even in subjects infected with $H$ pylori, a considerable proportion of ulcers seems to be due to other causes. Heterogeneous results have similarly been reported for the $H$ pylori-gastric cancer association.

There are two primary reasons why disease is so variably attributed to $H$ pylori. Firstly, the imperfect sensitivity and specificity of diagnostic tests for $H$ pylori result in an inaccurate measure of the relative risk (RR) for disease in infected people. For example, let us suppose that investigators are studying peptic ulcer disease (PUD) in a population with $40 \% \mathrm{H}$ pylori prevalence and, in conducting their study, use a diagnostic test for $H$ pylori with $90 \%$ sensitivity and specificity. If these hypothetical investigators observe a RR for PUD of 2.2 in infected subjects, they will have underestimated the true RR (3.3) by 33\% (for details on methods, see Kleinbaum and colleagues ${ }^{29}$ ). If the diagnosis of the disease also is subject to some misclassi- fication (that is, there may be some subjects with undiagnosed PUD), the RR could be further affected.

The second reason disease is so variably attributed to $H$ pylor $i$ is that the prevalence of $H$ pylori varies from population to population. This causes different estimations of the portion of disease attributable to infection (the population attributable risk (PAR)). PAR is dependent on both $R R$ for disease and on the prevalence of infection:

$(\operatorname{PAR}=[\mathrm{p}(\mathrm{RR}-1)] /[\mathrm{p}(\mathrm{RR}-1)+1]$

where $\mathrm{p}$ is the prevalence of $H$ pylori in the populations). ${ }^{29}$ Thus, assuming the relative risk for disease is the same from population to population, then the prevalence of $H$ pylori will determine how much disease is related to infection in a given population. For example, in many communities worldwide, the prevalence of $H$ pylori is as high as $50 \%$. In wealthy communities in the United States, however, prevalence of $H$ pylori may be as low as $20 \%$. This difference in $H$ pylori prevalence would translate into a considerable difference in the PAR. Assuming a RR of 3.3 in both settings, the proportion of PUD caused by $H$ pylori would be $53 \%$ in the high prevalence community compared with only $32 \%$ in the low prevalence community.

So what proportion of disease really is caused by $H$ pylori? Recently, Pisani et al calculated that $55 \%$ of gastric cancers worldwide were due to $H$ pylori infection. ${ }^{2}$ In a similar meta-analysis, Kurata et al calculated that between 48 and $64 \%$ of peptic ulcers were caused by $H$ pylori. ${ }^{30}$ These calculations are likely to underestimate risk as use of imperfect diagnostic tests in the analysed studies would tend to negatively bias findings. ${ }^{29}$ The paper by Kurata et al may also inaccurately reflect global risk for PUD by evaluating only United States populations; these populations may differ significantly from others worldwide in the prevalence of potentially confounding PUD risk factors such as cigarette smoking and use of non-steroidal anti-inflammatory agents. The problem of risk measurement is even more complicated in the case of gastric cancer because misclassification of antecedent infection may be more pronounced in cancer cases than in the population at large. Conversely, Pisani et al's calculations would also tend to overestimate the proportion of cancers attributable to infection because they considered all gastric adenocarcinomas to be similarly related to infection. It is now thought that cancers in the proximal stomach, which account for up to $50 \%$ of cancers in industrialised countries, are 
not linked to $H$ pylori. Thus, these tumours should not be considered in overall calculations of PAR.

In table 1, I extrapolate on Pisani et al's and Kurata et al's work, taking into account the likely underestimation of RR caused by using imperfect diagnostic tests ${ }^{30}$ and including only distal cancers in the calculations. It is assumed that diagnostic tests for $\mathrm{H}$ pylori are $90 \%$ sensitive and specific for infection in the industrialised countries where the tests were developed and are somewhat less sensitive and specific in developing countries ( $85 \%$ sensitivity and specificity). It is also assumed that $10 \%$ of ulcers may remain undiagnosed either due to empirical treatment without diagnostic testing or to lack of symptoms. In industrialised countries, I assumed that $60 \%$ of cancers occurred in the distal stomach compared with $90 \%$ in developing countries. Based on these assumptions, it can be seen that the RRs for cancer and for ulcer disease rise substantially (from 1.5/3.0 to 5.1 for cancer and from 3.3 to 6.3 for ulcer disease). The PAR also rises correspondingly with $56 \%$ of cancers and $76 \%$ of ulcers due to $H$ pylori. It should be noted, however, that these figures will vary widely from population to population based on infection prevalence. Thus, only one third of gastric cancers in industrialised nations are due to infection compared with two thirds in the developing world.

Using these adjusted RRs, one can also calculate the proportion of disease in infected people that is due to infection [attributable risk in the exposed $=(R R-1) / R R)]$. This is particularly important for patients with duodenal ulcer disease as the attributable risk in the exposed can predict the failure rate of duodenal ulcer treatment in patients in whom infection is successfully eradicated. Using the adjusted RR in table 1 one would expect $H$ pylori eradication to cure $80 \%$ of duodenal ulcers leaving $20 \%$ to relapse despite successful eradication therapy. This is remarkably similar to the actual findings reported by Laine et al. ${ }^{28}$

Thus, based on adjusted calculations of PAR, it seems that, worldwide, at least 5000000 new cases of gastric cancer and duodenal ulcer disease due to $H$ pylori occur each year. If one further considers that $H$ pylori causes gastric ulcers and may lead to other diseases and syndromes as well, the magnitude of sickness due to this single organism reaches truly frightening proportions.

\section{$H$ pylori-stamp it out or "live and let die"?}

$H$ pylori infection is decreasing in frequency worldwide. By some reports, infection in children is almost non-existent. Moreover, the diseases associated with $H$ pylori are either rare (gastric lymphoma) or decreasing in incidence despite lack of $H$ pylori directed intervention (gastric cancer and duodenal ulcer disease). Data from the International Agency for Research on Cancer indicate that gastric cancer incidence has decreased almost in parallel worldwide at rates ranging between $10 \%$ and $19 \%$ per decade. ${ }^{31}$ This occurred despite the increase in non-H pylori related tumours of the proximal stomach. The rates of decline for duodenal ulcer disease are more difficult to determine but certainly, the incidence of serious morbidity (major bleeding) and/or mortality have declined considerably in industrialised nations. ${ }^{32}{ }^{33}$ Even with these favourable trends, however, the magnitude of morbidity and mortality engendered by $H$ pylori continues to be sizable. Unfortunately, the regions where $H$ pylori is most prevalent and where benefits are most likely to be realised, are often those with the least resources for large eradication programmes. Yet, the time has come to test the effects of $H$ pylori eradication on morbidity and mortality in large populations. It is only by knowing how $H$ pylori eradication contributes to not only cancer and ulcer disease, but also to overall mortality and morbidity, that we rationally determine the magnitude of disease and formulate public health strategies to combat this formidable organism.

1 Blaser MJ. Helicobacter pylori eradication and its implicaions for the future. Aliment Pharmacol Ther 1997;11(suppl 1):103-7.

2 Pisani P, Parkin DM, Munoz N, et al. Cancer and infection: estimates of the attributable fraction in 1900. Cancer Epidemiology, Biomarkers and Prevention 1997;6:389-400.

3 Taylor DN, Parsonnet J. The epidemiology and natural history of Helicobacter pylori infection. In: Blaser MJ, Smith PD, Ravdin JI, Greenberg HB, Guerrant RL, eds. Infections of the gastrointestinal tract. New York: Raven Press, 1995:551-64

4 Parsonnet J, Blaser MJ, Perez-Perez GI, et al. Symptoms and risk factors of Helicobacter pylori infection in a cohort of epidemiologists. Gastroenterology 1992;102:41-6.

5 Banatvala N, Mayo K, Megraud F, et al. The cohort effect Banatvala N, Mayo K, Megraud F, et al. The cohort effec
and Helicobacter pylori. F Infect Dis 1993;168:219-21.

6 Cullen DJE, Collins BJ, Christiansen KJ, et al. When is Cullen DJE, Collins BJ, Christiansen KJ, et al. When is
Helicobacter pylori infection acquired? Gut 1993;34: Helicobact

7 Parsonnet J. The incidence of Helicobacter pylori infection. Aliment Pharmacol Ther 1995;9(suppl 2):45-52

8 Replogle ML, Glaser SL, Hiatt RA, et al. Biological sex as a risk factor for Helicobacter pylori infection in healthy young adults. Am F Epidemiol 1995;142:856-63.

9 Bohmer CJ, Klinkenberg-Knol EC, Kuipers EJ, et al. The prevalence of Helicobacter pylori infection among inhabitants and healthy employees of institutes for the intellectually disabled. Am F Gastroenterol 1997;92:1000-4.

10 Goodman KJ, Correa P, Tengana Aux HJ, et al. Helicobacter pylori infection in the Colombian Andes: a populationbased study of transmission pathways. Am $\mathscr{f}$ Epidemiol 1996;144:290-9.

11 Eurogast Study Group. Epidemiology of, and risk factors for, Helicobacter pylori infection among 3194 asymptofor, Helicobacter pylori infection among 3194 asymp

12 Hopkins RJ, Russell RG, O'Donnoghue JM, et al. Seroprevalence of Helicobacter pylori in Seventh-Day Adventists and other groups in Maryland. Lack of association with diet. Arch Intern Med 1990;150:2347-8.

13 Malaty HM, Graham DY. Importance of childhood socioeconomic status on the current prevalence of Helicobacter pylori infection. Gut 1994;35:742-5.

14 Smoak BL, Kelley PW, Taylor DN. Seroprevalence of Helicobacter pylori infection in a cohort of US Army recruits. Am $\mathcal{F}$ Epidemiol 1994;139:513-19.

15 Teh BH, Lin JT, Pan WH, et al. Seroprevalence and associated risk factors of Helicobacter pylori infection in Taiwan. Anticancer Res 1994;14:1389-92.

16 Blecker U, Hauser B, Lanciers S, et al. The prevalence of Helicobacter pylori-positive serology in asymptomatic chilHelicobacter pylori-positive serology in asymptom
dren. F Pediatr Gastroenterol Nutr 1993;16:252-6.

17 Malaty HM, Engstrand L, Pedersen NL, et al. Helicobacter pylori infection: genetic and environmental influences. Ann Intern Med 1994;120:982-6.

18 Lambert JR. The role of Helicobacter pylori in nonulcer dyspepsia. A debate-for. Gastroenterol Clin North Am 1993;22:141-51.

19 Lazzaroni M, Bargiggia S, Sangaletti O, et al. Eradication of Helicobacter pylori and long-term outcome of functional dyspepsia. A clinical endoscopic study. Dig Dis Sci 1996;41:1589-94.

20 Rinaldi V, Zullo A, Diana F, et al. Helicobacter pylori, hyperammonemia, and hepatic encephalopathy: is there a correlation [letter]? Am $\mathcal{F}$ Gastroenterol 1997;92:723-4.

21 Kolibasova K, Tothova I, Baumgartner J, et al. Eradication of Helicobacter pylori as the only successful treatment in of Helicobacter pylori as the only successful trea

22 Patel P, Mendall MA, Carrington D, et al. Association of Helicobacter pylori and Chlamydia pneumoniae infections 
with coronary heart disease and cardiovascular risk factors. BMF 1995;311:711-14

23 Sullivan PB, Thomas JE, Wight DG, et al. Helicobacter pylori in Gambian children with chronic diarrhoea and malnutrition. Arch Dis Child 1990;65:189-91.

24 Kurata JH, Haile BM. Epidemiology of peptic ulcer disease. Clin Gastroenterol 1984;13:289-307.

25 Maher W, Jyotheeswaran S, Potter G, et al. An epidemiological study of peptic ulcer disease patients in greater Rochester, New York [abstract]. Gastroenterology 1997;112:A206.

26 Gislason G, Emu B, Okolo P, et al. Where have all the Helicobacter gone: etiologic factors in patients with duodenal ulcers (DU) presenting to a university hospital [abstract] Gastrointest Endosc 1997;45:263.

27 Greenberg PD, Albert CM, Ridker PM, et al. Helicobacter pylori as a risk factor for peptic ulcers in patients taking low-dose aspirin [abstract]. Gastroenterology 1997;112: A133.

28 Laine L, Hopkins RJ, Girardi LS. Has the impact of $\mathrm{H}$. pylori therapy on duodenal ulcer recurrence in the U.S. been overstated: a meta-analysis of rigorously-designed trials [abstract]. Gastroenterology 1997;112:A192.

29 Kleinbaum DG, Kupper LL, Morgenstern H. Epidemiologic research. New York: Van Nostrand Reinhold Co., 1982: 221-41

30 Kurata JH, Nogawa AN. Meta-analysis of risk factors for peptic ulcer. F Clin Gastrenterol 1997;24:2-17.

31 Coleman MP, Esteve J, Damiecki P, et al. Trends in cancer incidence and mortality. Lyon: International Agency for Research on Cancer, 1993:193-224.

32 Kurata JH, Elashoff JD, Haile BM, et al. A reappraisal of time trends in ulcer disease and factors related to changes in ulcer hospitalization and mortality rates. Am f Public Health 1983;73:1066-72.

33 Sonnenberg A. Temporal trends and geographical variations of peptic ulcer disease. Aliment Pharmacol Ther 1996; 9(suppl 2):3-12. 